\title{
A Discussion on Rationalism of Ancient Greek Art and Its Influences in History
}

\author{
Zhiyong Wang \\ School of Fine Arts, Sichuan University of Science and Engineering, Zigong, China
}

Email address:

matinee2005@aliyun.com

\section{To cite this article:}

Zhiyong Wang. A Discussion on Rationalism of Ancient Greek Art and Its Influences in History. International Journal of Literature and Arts. Vol. 4, No. 3, 2016, pp. 30-33. doi: 10.11648/j.ijla.20160403.11

Received: March 29, 2016; Accepted: April 9, 2016; Published: April 27, 2016

\begin{abstract}
Western civilisation originated in the age of ancient Greece. The general characteristics of western civilisation have ever suggested their original source from ancient Greek culture, in which, the idea "rationalism" has been viewed as the main property of cultural foundation. This very idea was not only showed upon the western ancient philosophy, the principles and the applications of modern science and technologies, but it also unfolded its ray in the region of western literature and arts. Particularly, the tendency of "rationalism" revealed itself in many periods of western art history. Under a brief historical review and the method of morphological research in visual form, this discussion tried to clarify the idea of "rationalism", which embodied itself in many masterful works of different historical ages or presented its effects on such aesthetic standards as "imitation" and "ideal" in history. As the result, it will be exhibited clearly the historical evolution of this idea and its relationship with the development of western art and culture.
\end{abstract}

Keywords: Western Civilisation, Western Art, Rationalism, Idea

\section{Introduction: The Contribution of Thinkers}

Immanuel Kant had commented ancient Greek thoughts in his philosophy critique: Greeks firstly began to think in philosophical way among all ancient nations. For they tried to avoid following the trace of images, they were to cultivate rational knowledge with abstraction. Instead, the other nations always had the concepts intelligible by concreteness of image [1]. Such contribution came at first from ancient Greek philosophers. Thales, Pythagoras, and Heraclitus could be the representatives, but Socrates, Plato, and Aristotle were the best well known. The reason why they were mentioned here in advance is, as the agents of ancient Greek thoughts, they provided a foundation for thinking way in that civilisation region. Although they presented in diversified even opposite methods in our minds, we still discover the consistency under the multifarious expresses. We call such think way as "rationalism". Socrates had stated "the unexamined life is not worth living". This remembered sentence once reflected their characteristics of prudence and reason. So, the author of $A$ Global History has said the ancient Greek spirit: they explored everything, and put them on trial of reason [2]. We could have some associations to this narration: since ancient Greeks have been accustomed to such way of thinking, they must have the similar imprinting in other aspects of social life. Still in the same book A Global History, Stavrianos remarked: the combination of rationalism and realism made the Greeks pondered over all human and social questions freely and fancifully, and expressed their thoughts and feelings in great literature, philosophy, and art, they are significant and draw intensive attentions till now [2]. This statement hit a key point. It is that rationalism may deeply influence the artistic creativity of ancient Greece.

\section{The Rational Spirit of Ancient Greek Art}

If compared with ancient Egyptian art, we could have a better understanding upon rationalism in Greek art. The ancient Greek art indeed received affect from ancient Egypt in its early age, but then, it developed its own attributes gradually. The invention of "foreshortening" in painting was ever an important landmark within such development [3]. The 
perspective contradiction of ancient Egyptian art had been overcome by Greek artists. They began to make realistic visual observation as the basis of artistic creation [3]. There is no doubt that the realistic observation basis disclosed the reason hold by Greeks at that time. In the process of artistic creation, the Greek arts already had the objects into perspective space which they had recognised logically. There was an essential concept in ancient Greek aesthetics. Imitation was the name. Imitation itself contained the factor of rational cognition. However, the imitation in ancient Greek mind was not ever the photographic copy in present. Their imitation was viewed as a way for realisation of ideas. On the concept of imitation as ancient Greek aesthetical thought, Lionello Venturi has told that imitation of nature is necessary, but similarly, idealisation of nature is also necessary, which accord with physical and ethical good, and conform to mathematical relationship and noble sentiments [4]. The idealised art by imitation corresponded to their rationalism. It could be regarded as artistic manifestation of such idea. Another point is worthy to be mentioned here, it is the scientific trend in ancient Greek art. The mathematical idea of Pythagoras gave a foundation for their relationship, as he said "Everything is number" [5]. Indeed, the thinking way of "Everything is number" permeated into art and evolved to arithmetic or geometric analysis and the consequent emphasis on form and scale. When talking about an ancient Greek painter, Xenocrates said that his general contribution was the scientific base for painting [4]. The intensive consideration of form and scale were still obvious in ancient Greek architecture. This idea was already developed into a series principle terms. Vitruvius commented the architectural design with the words as "regulation", "placement", and "symmetry". The ancient Greek architectures had more rational characteristics than other artistic categories. The theme of ancient Greek architecture was shrine building, whose architectural configuration parallelised with the ideal purpose. If compared such style (and its successors in the age of ancient Rome, Renaissance, and Neoclassicism) with other architectural styles as Baroque or romanticism, we could easily find the keynote of solemn and rationality, which was expressed very well in Argive Heraion and Parthenon with Dorian style (Figure 1). Only had ignored the detailed rilievo decoration, it appeared instantly the geometrical abstraction as a whole, which presented the absolute idea of spirit in a perfect way. Moreover, it contained the rigorous mathematical logic narrated above to define its form:

Ancient Greek architecture was based upon a set of mathematical relation. Its key point was "modulus": that is the diameter or radius which was under the column. The height and distance of column, even the size of architecture as whole were all relayed on this "modulus", which could keep the correct relationship in scale between whole and parts. It did reflect the idea of harmony in ancient Greek philosophy. There were certain relationships of scale within all things in nature. Human were the lord of creation produced by god, so the Greeks were inspired by the relationships between parts of human body, applied them into the designs of column and shrine building. [6]

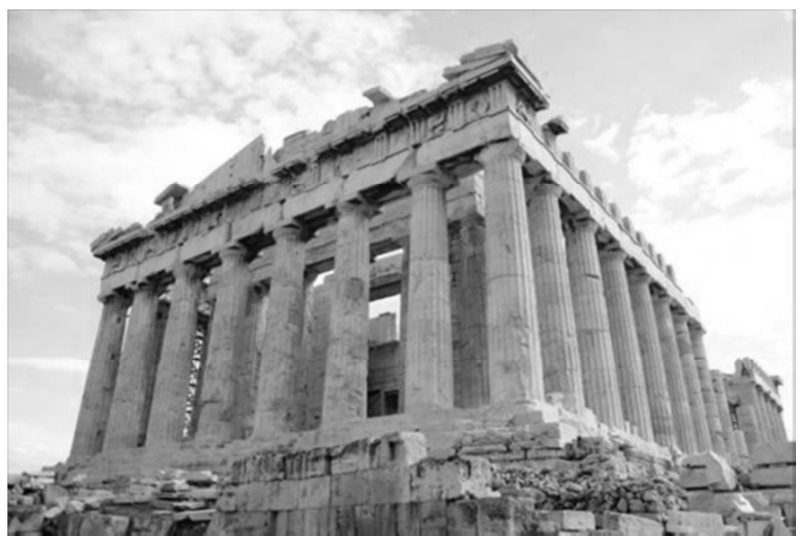

Figure 1. Parthenon

This idea provided a spiritual basis for ancient Greek art and architecture. It built the groundwork for numerous artistic forms in later age as well. The historical process will gradually demonstrate them.

\section{Influences in History}

If recalled the art of middle ages in a historical perspective, it seemed far away from "rationalism". Although Gothic churches implied the ideal "City of God", its pinnacle could easily have people associated it with passionate expressionism. The illustrations in religious books would hardly present the same visual cognition as in ancient Greece. Ernst $\mathrm{H}$. Gombrich commented in his work The Story of Art: the Greeks drew what they saw, but the artists in middle ages drew what they felt [3]. Venturi explained it as the brilliant achievements of medieval architecture were ever based upon the ridding of early mathematic principles. However, it was just a latent state, the radiance of reason emerged again in the end of Medieval. As the representative of Florence school, Giotto's painting showed a new turning point. Depth cueing with perspective effect reappeared in his fresco: Italian artists began to resume the Greek sight on art. Masaccio even went farter. He strictly combined the mathematic rules into painting perspective, and his work illustrated commendably his point of view. Then, the painting way of "linear perspective" was invented by another Florence artist named Filippo Brunelleschi. His contributions were also included in architectural art. The typical characters of classical building displayed by his hands, and the churches with concordant relationship in scale were to replace the radical Gothic style [3]. However, the achievements of Leonardo da Vinci became the best interpretation on the relationship between Greek artistic spirit and Renaissance. We can not only define this historical figure with simple term of "artist". Although he created masterpieces as The Last Supper or Mona Lisa, he still anatomised corpse, designed weapon, and even studied on physical law. Such activities were just the work burdened by later scientists and engineers with their intelligence (we can not ignore the similarity between standard proportions of the human figure of Leonardo da Vinci and modern ergonomics). For Leonardo da Vinci, the painting was a way to explore the universe, but not the 
exclusive one (Figure 2). Idealism was revealed itself again in Renaissance. The sculpture David of Michelangelo, it unfolded the externalisation of idea, instead of expression of emotion. Such an externalised process of shaping cast the light of reason.

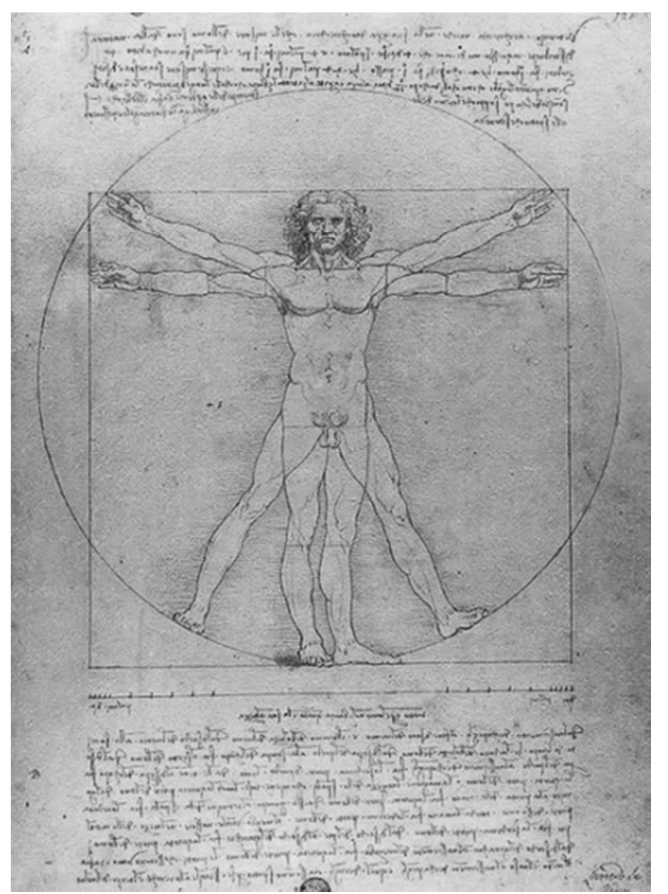

Figure 2. Vitruvian Man, by Leonardo da Vinci.

Neoclassicism was once the major successor of ancient Greek spirit after Renaissance. The activists of neoclassicism competed by reason and solemnity with preciosity of rococo style. Nicolas Poussin and Jacques Louis David became the new representatives of rationalism (Figure 3). In the field of architecture, the similar inheritance was continued as well. Like Pantheon in France, Brandenburger Tor in Germany, and Capitol in America, they all paid a tribute to harmonious classical structure forms with their visual language in every detail.

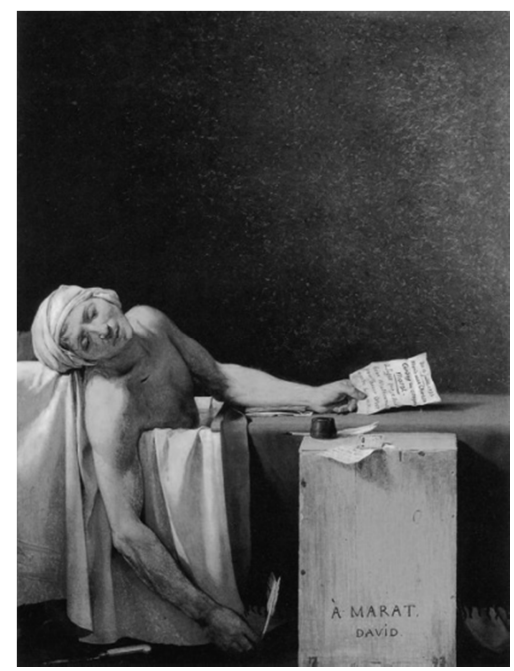

Figure 3. The Death of Marat, by Jacques Louis David.
The development of western art faced a complicated situation after the birth of modernism. There were some artists with rationalism tendency as Paul Cezanne and Piet Cornelies Mondrian in that time, but drain of emotion and awareness of irrationalism was becoming the fundamental key. We could easily find its manifestation in the works from Edvard Munch and surrealists (Figure 4). Similarly as in Medieval, the rationality began to fall into the state of dormancy again. However, the western art after modernism can hardly have any rational ideal: it was a post-morality age dominated by the sensory. The architectural creations were able to be the sole identity of rational spirit. The term "new objective" (Neue Sachlichkeit in German) was the best notion for such a circumstances. As opposed to mania in modern art, modern architecture (along with industrial design since modern age) revealed reasoning and logic everywhere (Figure 5). In architecture, as the equivalent concept of modernism, functionalism just meant producing rationality. Then, after the experience of enlightenment, the science and technology made an unbelievable progress in modern age. If we review them as an artistic perspective, is such achievement not a masterpiece of art? It has us associate with the opinion of Friedrich Hegel: the history is evolution of spirit, or it is realisation of idea [7].

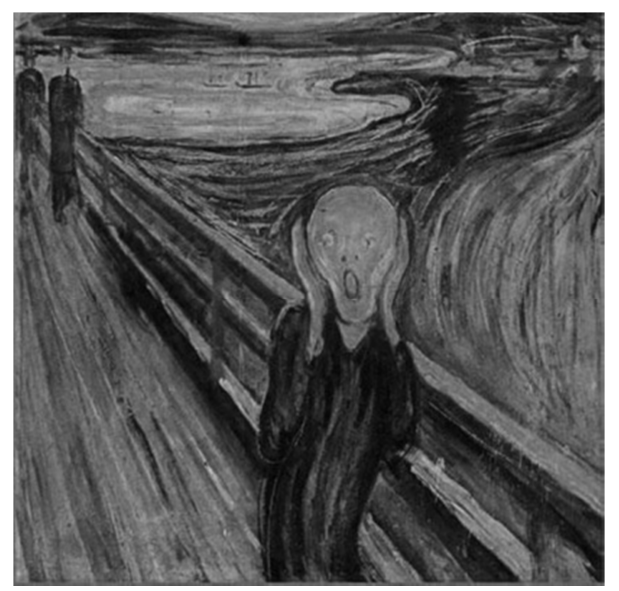

Figure 4. The Scream, by Edvard Munch.

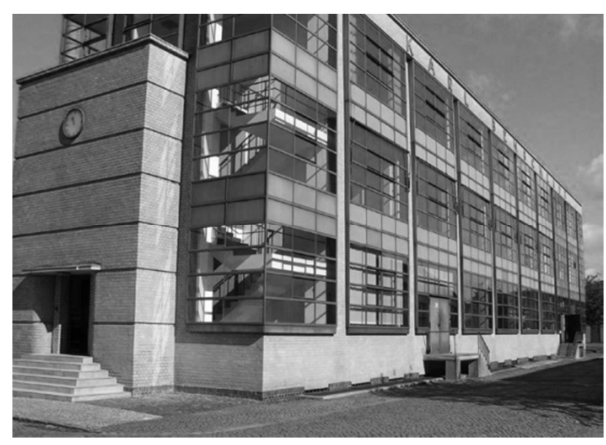

Figure 5. Fagus Factory, By Walter Gropius.

\section{Conclusions}

Oswald Spengler had argued that each type of culture possessed the holistic property [8]. Such holistic essence 
could be interpreted in two aspects. Firstly, from the horizontal perspective, culture never expresses itself in isolation. It must be unfolded in different fields with diversified ways, which hence revealed the same cultural origin. That means a type of culture could make self-expression in those fields as technology, economy, politics, ethics, and art, but they all were dominated totally by the same cultural system. Similarly, from the longitudinal perspective, culture can hardly exist isolated in history. As the foundation of any civilisation, culture would influence the various patterns of manifestation in long term of history. The rational spirit of ancient Greece actually exhibited itself by the evolution of western art in the latter perspective. In the field of art, the rationalism established itself in ancient Greek artistic creations at first. After a concealed period of middle ages, it reappeared again as painting, sculpture and architecture in Renaissance and then in neoclassicism. Although went through the modern age, the rationalism would not be the focus in art, it displayed the same spirit in modern design with the background of rationalised science and technology if we view it as an artistic pioneering work of history.

\section{References}

[1] Immanuel Kant, Logik Ein Handbuch zu Vorlesungen, The Commercial Press, Beijing, 1991.
[2] Leften Stavros Stavrianos, A Global History, Vol. 1, Peking University Press, Beijing, 2006.

[3] Ernst H. Gombrich, The Story of Art, Tianjin People's Fine Arts Publishing House, Tianjin, 1998.

[4] Lionello Venturi, The Critical History of Western Art, Jiangsu Education Publishing House, Nanjing, 2005.

[5] Bertrand Russell, History of Western Philosophy, Vol. 1, The Commercial Press, Beijing, 2004.

[6] Chenping, History of World Architecture: From Remote Antiquity to 19th Century, Southeast University Press, Nanjing, 2006.

[7] Friedrich Hegel, The Philosophy of History, Shanghai Bookstore Publishing House, Shanghai, 2006.

[8] Oswald Spengler, The Decline of the West, SDX Joint Publishing Company, Shanghai, 2006.

[9] Wang Shouzhi, A History of Modern Design, China Youth Press, Beijing, 2002.

[10] Peter Burke, History and Social Theory, Shanghai People's Publishing House, Shanghai, 2010.

[11] Arthur S Marks, Rediscovering Greek Architecture and Discovering the Attic Order, Transactions of the American Philosophical Society, 2013, Vol. 103 (5): pp.5,7-14.

[12] Ralph Croizier, Modernism(s) and Global Modernity(ies): what can modern art offer to global history?, Journal of Global History, 2014, Vol. 9 (1): pp.162-167. 